\title{
Energy and Exergy Analysis of a Power Plant Based on a Three Reactor Chemical Looping Reforming System
}

\author{
Mohammed N. Khan, Tariq Shamim* \\ Institute Center for Energy (iEnergy), Department of Mechanical and Materials Engineering, Masdar Institute of \\ Science and Technology, Masdar City, Abu Dhabi, United Arab Emirates
}

\begin{abstract}
Chemical looping reforming (CLR) is an innovative way of simultaneously producing hydrogen $\left(\mathrm{H}_{2}\right)$ and capturing carbon dioxide $\left(\mathrm{CO}_{2}\right)$. In CLR process the fuel and the oxidizer do not meet and therefore, there is no energy penalty for separating $\mathrm{CO}_{2}$ as opposed to the conventional power plants. Only thing required to do to obtain pure $\mathrm{H}_{2}$ and $\mathrm{CO}_{2}$ is to condense the water vapor in both the streams. The process is divided into three steps: oxidation of fuel in the fuel reactor (FR) to form $\mathrm{CO}_{2}$ and $\mathrm{H}_{2} \mathrm{O}$, reduction of steam to form $\mathrm{H}_{2}$ in the steam reactor (SR) and the complete oxidation of the metal oxygen carrier (OC) in the air reactor (AR). When the CLR system is integrated with a full power plant, there are energy losses in each of the components. It is necessary to know where the exergy is being destroyed and where it can be avoided. Therefore, an exergy analysis has been performed on the plant consisting of CLR system, steam cycle (SC) which incorporates triple pressure heat recovery steam generator (HRSG) and the compression system for compressing $\mathrm{H}_{2}$ and $\mathrm{CO}_{2}$ to high pressures ready for consumption or sequestration. This study employs an Aspen plus model to investigate the influences of various operating parameters such as the flow rates of fuel, air, steam and OC on the electrical, $\mathrm{H}_{2}$ and exergetic efficiencies of the plant.

The results show that the electrical and the $\mathrm{H}_{2}$ efficiencies are dependent on the reactor temperatures. The reactor temperatures can be easily controlled by varying the flow rates of the reactants. It is observed from the results that higher electrical efficiencies are obtained at lower fuel, steam and air flow rates and higher OC flow rates. While the higher $\mathrm{H}_{2}$ efficiencies are obtained at lower flow rates of OC, air and steam and higher flow rates of fuel. Since the exergetic efficiency depend on the output of the plant which is $\mathrm{H}_{2}$, then the similar criteria is required to obtain high exergetic efficiency as that of $\mathrm{H}_{2}$ efficiency.
\end{abstract}

Keywords: Hydrogen Production, Chemical Looping Reforming, Exergy Analysis, Aspen Plus, Hydrogen Efficiency.

\section{Introduction}

Hydrogen $\left(\mathrm{H}_{2}\right)$ generation has always been the subject of vigorous research. It is a clean fuel which produces water when combusted, a favorable outcome for curbing the emissions of greenhouse gases. In the current energy scenario, the diversification of energy sources is an essential requirement [1]. Due to the increased energy demand lately and due to rapid depletion of fossil fuels, the attention has been shifted in discovering and developing clean energy sources like the renewables such as solar, wind etc. However, these sources are intermittent and hence, researchers are also focusing on finding efficient ways to produce clean fuels like $\mathrm{H}_{2}$. But it is only a secondary or intermediate energy carrier. It has to be produced

${ }^{*}$ Corresponding author

E-mail: tshamim@masdar.ac.ae

(C) 2016 International Association for Sharing Knowledge and Sustainability

DOI: $10.5383 /$ ijtee.11.02.007 from the primary fossil fuels. $\mathrm{H}_{2}$ is produced mostly by steam reforming of methane or natural gas. Currently, the production is more than 1 billion $\mathrm{m}^{3} /$ day comprising of $48 \%$ from natural gas, $30 \%$ from oil, $18 \%$ from coal and the rest from electrolysis [2-3]. The other ways of producing $\mathrm{H}_{2}$ is the $\mathrm{H}_{2} \mathrm{O}$-gas shift reaction, thermal decomposition, auto-thermal reforming, catalytic oxidation, pyrolysis and steam gasification [4-5]. Nevertheless, the use of fossil fuels for $\mathrm{H}_{2}$ production increases the emissions of greenhouse gases. Most of the current production technologies of $\mathrm{H}_{2}$ from fossil fuels employ a $\mathrm{CO}_{2}$ separation module to separate pure $\mathrm{H}_{2}$ from the gas mixtures of $\mathrm{CH}_{4}, \mathrm{CO}, \mathrm{CO}_{2}$ and $\mathrm{H}_{2}[6]$. It has been estimated that about $22 \%$ 
of the total $\mathrm{H}_{2}$ production cost is for separating $\mathrm{CO}_{2}$ [7]. Therefore, there has to be a sustainable and eco-friendly production process. Chemical looping reforming (CLR) is an innovative $\mathrm{H}_{2}$ production process that possesses all the necessary requirements for a production technology to be sustainable.

CLR process with three reactors is a novel method with inherent $\mathrm{CO}_{2}$ separation and high $\mathrm{H}_{2}$ yield with no additional separation modules and hence, no energy penalty. In this process, the oxygen $\left(\mathrm{O}_{2}\right)$ in transition metal oxygen carrier $(\mathrm{OC})$ is utilized to reduce the fuel into $\mathrm{CO}_{2}$ and $\mathrm{H}_{2} \mathrm{O}$ in the fuel reactor (FR) undergoing an endothermic reaction. Then the reduced $\mathrm{OC}$ goes into the steam reactor (SR) to react with steam and forms $\mathrm{H}_{2}$ in a slightly exothermic reaction. The oxidized OC goes into the air reactor (AR) to get fully oxidized in a highly exothermic oxidation reaction. The schematic of the CLR process is shown in Fig. 1. Few thermodynamic studies have been performed on this system which endorses the advantages of the CLR process. Chiesa et al. [8] were one of the first to introduce and test the concept of three reactors in a loop. They had proposed two different plant configurations and compared them with the already available $\mathrm{H}_{2}$ production technologies in the market. The results were in favor of CLR process and showed its excellent benefits. Xiang et al. [9] proposed two fuel reactors to ensure complete conversion of the fuel. The fuel gas was obtained through gasification of the coal which is made to react with iron oxide as an OC. High conversion efficiency of the fuel was reported as they had used two fuel reactors. Cormos [10] analyzed CLR with the natural gas and the synthesis gas produced from coal. Recommendations about increasing the overall energy efficiency and the methodology to evaluate the performance based on critical design factors has been discussed. Recently, in our previous work [11], we have identified the key operating parameters like the flow rates of the air, fuel, steam and $\mathrm{OC}$ and analyzed their influence on the $\mathrm{H}_{2}$ and $\mathrm{CO}_{2}$ production and the exergetic efficiency of the CLR system itself. However, in that study, the CLR system was not integrated with any power plant scheme. Hence, it did not gave an overall exergetic impression of the CLR integrated power plant.

Exergetic analysis of a system is an excellent way of knowing where the energy wastage is happening and where it can be avoided. Several exergy studies have been performed on the power plants based on chemical looping combustion (CLC) system. Anheden and Svedberg [12] were the first ones to perform such analysis on a dual loop CLC system. They reported that exergy destruction due to the fuel combustion is much smaller in the CLC system compared to the conventional combustion system, which enhances the net plant efficiency significantly. A similar but comprehensive study has been performed by Hassan and Shamim [13] on a similar dual loop system and studied the influence of varying the key operating parameters. The optimum operating parameters which results in higher exergetic efficiencies were reported. To the knowledge of the authors there is no study concerning the exergy analysis on a CLR system based power plant. But there are few exergy studies which have been performed on other $\mathrm{H}_{2}$ producing systems such as the steam methane reforming. One such study is by Simpson and Lutz [14]. They have analyzed a steam methane reforming system and reported that a majority of the exergy destruction occurs due to high irreversibility of chemical reactions and heat transfer. Moreover, a significant amount of exergy is wasted in the exhaust streams. It has been suggested

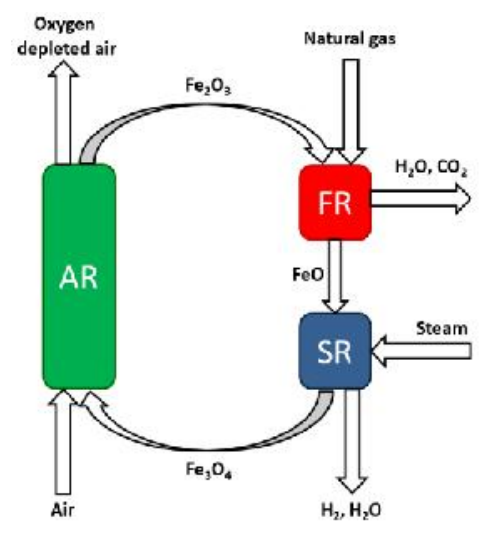

Fig. 1. Schematic of a Three Reactor CLR Process

that the exergy destruction by the chemical reactions should be reduced, which is possible in the CLR system.

The simulations are performed for different mass flow rates of air, fuel, steam and OC. The thermodynamic data obtained from the full plant simulations is used to calculate the electrical, $\mathrm{H}_{2}$, global and exergetic efficiencies of the overall plant. Performance sensitivity of the whole system to the variation in operating parameters has been studied. The results obtained will help in reducing the losses and provide guidance for enhancing the system design.

\section{Methodology}

The process flow model of the three reactor arrangement and the power producing plant is built in Aspen plus. The model is developed by considering the conservation of mass and energy for all the components. Thermodynamic equilibrium is assumed for all the calculations. The properties are evaluated based on the Redlich-Kwong-Soave (RKS) equation of state with Boston-Mathias modifications. The composition of the products in the reactors is calculated using Gibbs energy minimization concept. The fuel used is natural gas and the OC used is iron oxide with $70 \%$ (by weight) inert material $\mathrm{MgAl}_{2} \mathrm{O}_{4}$. Iron oxide is chosen since it is cheap and abundantly available in nature and it has been recommended in the literature for use in $\mathrm{H}_{2}$ production technologies. The possible reactions in each of the reactors are given below. In FR, the highest oxidation state of iron hematite $\left(\mathrm{Fe}_{2} \mathrm{O}_{3}\right)$ is introduced which undergo endothermic reaction (1) with natural gas to produce $\mathrm{CO}_{2}$ and $\mathrm{H}_{2} \mathrm{O}$ and gives a reduced oxidation state of iron called wustite $(\mathrm{FeO}) . \mathrm{FeO}$ reacts with steam in SR exothermically to form $\mathrm{H}_{2}$ and magnetite $\left(\mathrm{Fe}_{3} \mathrm{O}_{4}\right)$ in the products as shown in reaction (2). $\mathrm{Fe}_{3} \mathrm{O}_{4}$ is completely oxidized to $\mathrm{Fe}_{2} \mathrm{O}_{3}$ in the AR where the reaction (3) is highly exothermic. This in fact maintain the thermal balance of the CLR system. However, in these simulations to make the process more realistic the products considered in $\mathrm{FR}$ are $\mathrm{CO}_{2}, \mathrm{CO}, \mathrm{H}_{2} \mathrm{O}, \mathrm{H}_{2}, \mathrm{CH}_{4}, \mathrm{Fe}_{3} \mathrm{O}_{4}, \mathrm{FeO}$ while in AR NOx formation has been assumed. The thermodynamic model has been validated with the data available in the literature [8] and it has been discussed in our previous work [11].

$4 \mathrm{Fe}_{2} \mathrm{O}_{3}+\mathrm{CH}_{4} \rightarrow 8 \mathrm{FeO}+2 \mathrm{H}_{2} \mathrm{O}+\mathrm{CO}_{2}-356.5 \mathrm{~kJ} / \mathrm{kmol}$ (reaction in FR)

$8 \mathrm{FeO}+8 / 3 \mathrm{H}_{2} \mathrm{O} \rightarrow 8 / 3 \mathrm{Fe}_{3} \mathrm{O}_{4}+8 / 3 \mathrm{H}_{2}+199.3 \mathrm{~kJ} / \mathrm{kmol}$ (reaction in $\mathrm{SR}$ )

$8 / 3 \mathrm{Fe}_{3} \mathrm{O}_{4}+2 / 3 \mathrm{O}_{2} \rightarrow 4 \mathrm{Fe}_{2} \mathrm{O}_{3}+314.6 \mathrm{~kJ} / \mathrm{kmol}$ (reaction in $\mathrm{AR}$ ) 


\subsection{Plant Configuration}

The block diagram of the plant with the components used in each of the blocks are listed in Fig. 2. RGIBBS reactor is used for FR, SR and AR, which assumes chemical and phase equilibrium based on the Gibbs energy minimization concept. Separation of solids and the product gases were assumed to be perfect and is done by using cyclones. A turbocharger is used for compression of incoming air into the AR to a desired pressure and power production through a gas turbine by the outgoing vitiated air from the AR. The exhaust of the AR is then used to generate intermediate pressure (IP) and low pressure (LP) steam in a heat recovery steam generator (HRSG). The exhausts from the FR and the SR are used to produce a high pressure (HP) steam in a parallel HRSG. In other words, a triple pressure HRSG has been employed for efficient utilization of the exhaust heat. The HP and IP steam are then supplied to the steam turbines (ST) to produce power. Some of the LP steam is compressed to IP steam to fulfill the steam requirement of the plant by using a steam compressor (SC). HRSG and ST unit constitute a steam cycle. The AR exhaust is then release into the atmosphere while the FR and SR exhausts are then compressed to the desired pressures in a two stage intercooled compression system. The main assumptions used for the plant are given in Table 1.

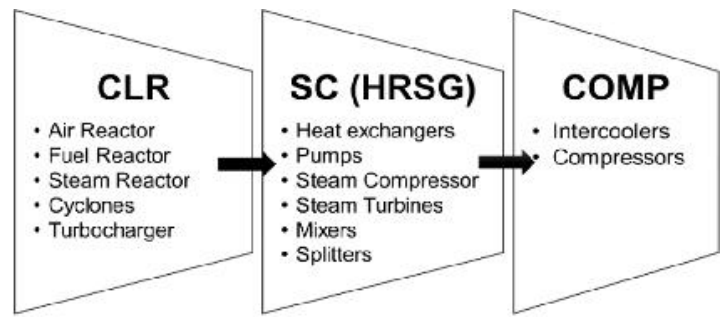

Fig. 2. Block diagram of a Plant with Components Used in each System

\subsection{Energy and Exergy Analysis}

For assessing the thermodynamic performance of the plant first law efficiencies can be used. An electrical efficiency and a hydrogen efficiency can be defined as follows

$$
\eta_{E}=\frac{E}{Q_{N G}} ; \eta_{E}=\frac{Q_{H}}{Q_{N G}}
$$

where $Q_{H}$ and $Q_{N G}$ are the thermal power (product of mass flow rate and LHV of the gas) of the $\mathrm{H}_{2}$ output and natural gas input respectively and $E$ is net work output. A single index called global efficiency can be define to include both the efficiencies and is given as

$$
\eta_{G L}=\frac{Q_{H}}{Q_{N G}-E / \eta_{E, R E F}}=\frac{\eta_{H}}{1-\eta_{E} / \eta_{E, P E F}}
$$

where $\eta_{E, R E F}$ is the reference electrical efficiency of an alternative power generation process used to deduct the equivalent natural gas consumption to produce the same amount of electricity actually produced by the plant. Such efficiency is assumed to be $50 \%$ [8].

The analysis based on first law does not provide information on the potential work lost in various processes during energy transformation. Therefore, a detailed exergy analysis based on both the first and second law of thermodynamics serves the purpose of accounting the irreversibilities. The exergy of a stream can be defined as the maximum amount of work that can
Table 1. Main Assumptions

\begin{tabular}{cc}
\hline Ambient conditions & $15^{\circ} \mathrm{C}, 1.013$ bar \\
\hline Natural gas heating value $(\mathrm{MJ} / \mathrm{kg})$ & 45.467 \\
Inert Material $\left(\mathrm{MgAl}_{2} \mathrm{O}_{4}\right)$ & $70 \%$ by weight \\
CL reactors operating pressures (bar) & AR-16, FR-20, SR-18 \\
CL reactors thermal losses & $0.2 \%$ of thermal input \\
CL reactors thermal losses & $0.2 \%$ of thermal input \\
Heat exchangers - Pressure loss & $2 \%$ \\
GT/TC compressor polytropic efficiency & 0.924 \\
GT/TC turbine polytropic efficiency & 0.926 \\
Steam cycle pressures (HP, IP, LP, & $90 / 22 / 3 / 0.04$ bar \\
Condensation) & $10 / 25 \mathrm{C}$ \\
HRSG pinch, approach temperature & $500 \mathrm{C}$ \\
Max. Turbine inlet temperature & $98 \%$ \\
Mechanical efficiency (pumps, & \\
compressors, turbines) & $85 \%$ \\
Isentropic efficiency (pumps, \\
compressors, turbines) \\
Liquid CO ${ }_{2}$ condition \\
$\mathrm{H}_{2}$ condition
\end{tabular}

be obtained when the stream goes from the current state to the dead state during which the stream may interact only with the environment. The dead state considered in this study is $T_{0}=25$ ${ }^{\circ} \mathrm{C}$ and $P_{0}=1 \mathrm{~atm}$. The total exergy is the combination of thermo-mechanical or physical and chemical exergies.

$$
E x_{\text {total }}=E_{p h}+E_{c h}
$$

The thermo-mechanical exergy is tabulated by using the enthalpy and entropy data from the simulations whereas the chemical exergies are tabulated using the standard chemical exergy information from Ref. [15].

$$
\begin{aligned}
& E x_{p h}=\left(H-H_{o}\right)-T_{o}\left(S-S_{o}\right) \\
& E x_{c h_{\text {total }}}=\sum_{i} x_{i} E x_{c h_{i}}+R T_{o} \sum_{i} x_{i} \ln x_{i}
\end{aligned}
$$

The overall exergetic efficiency is defined as the ratio of the exergies from the output streams $\left(\mathrm{H}_{2}\right.$ stream and net power $)$ and the input strearis.

$\eta_{E x}=\frac{E_{\mathrm{H}_{2}}+W_{\text {net }}}{E_{\text {lntet air }}+E_{\text {makeup water }}+E_{\text {intet fuel }}}$

\section{Results and Discussions}

The objective of this study is to analyze a three reactor CLR process with integrated power producing plant and compression system based on first and second law of thermodynamics. The base case results show that there is about $45.8 \%$ (by volume) conversion of steam into $\mathrm{H}_{2}$ in the SR. The gaseous products from the $\mathrm{AR}$ are argon (1.07\%), $\mathrm{CO}_{2}(0.03 \%), \mathrm{H}_{2} \mathrm{O}(1.2 \%), \mathrm{N}_{2}$ $(90.09 \%), \mathrm{O}_{2}(7.57 \%)$ and traces of $\mathrm{NO}$ while the products from the $\mathrm{FR}$ are $\mathrm{CO}_{2}(33.76 \%), \mathrm{H}_{2} \mathrm{O}(57.24 \%), \mathrm{H}_{2}(6.19 \%), \mathrm{CO}$ (2.53\%), $\mathrm{N}_{2}(0.24 \%)$ and traces of $\mathrm{CH}_{4}$. The electrical efficiency obtained is about $0.458 \%$ while the $\mathrm{H}_{2}$ efficiency of $70.96 \%$ giving a global efficiency of $71.62 \%$. The exergetic efficiency based on second law is about $69.36 \%$. Performance sensitivity of the plant based on the energy and exergy efficiencies for different values of the key operating parameters such as the mass flow rates of fuel, steam, air and OC have been studied. Performance is evaluated based on the electrical, hydrogen and 
exergetic efficiencies. Table 2 shows the values of the operating parameters considered. The chosen values are based on our previous work [11]. The following section discusses the results in detail.

Table 2. Range of Operating Parameters Studied

\begin{tabular}{cc}
\hline Operating parameter & Values (Bold - base case) \\
\hline Fuel mass flow rate $(\mathrm{kg} / \mathrm{s})$ & $\mathbf{7 . 6 3 9}, 8,8.2,8.4$ \\
Steam mass flow rate $(\mathrm{kg} / \mathrm{s})$ & $25,30,35, \mathbf{4 0 . 0 4}$ \\
Air mass flow rate $(\mathrm{kg} / \mathrm{s})$ & $45,50,55, \mathbf{5 9 . 3 7}$ \\
Excess OC $(\%)$ & $0, \mathbf{2}, 10,15$ \\
\hline
\end{tabular}

\subsection{Effect of Fuel Mass Flow Rate}

The fuel mass flow rate is varied from the base case value of $7.639 \mathrm{~kg} / \mathrm{s}$ to $8.4 \mathrm{~kg} / \mathrm{s}$ and the plant performance based on thermodynamic and exergetic efficiencies are plotted in Fig. 3. The base case value of the OC flow rate is $2 \%$ more than the stoichiometric amount to ensure the complete conversion of the fuel. With shift towards the fuel rich mixtures, a reduction in net work output (Table 3) occurs resulting in corresponding decrease in electrical efficiency. Likewise, the reactors outlet temperatures also decrease due to the utilization of more thermal energy supplied by the OC from the AR, as the fuel flow rate increases. This is because the endothermic reaction in the FR demands more thermal energy in order to satisfy the energy needed for the reaction to take place as the fuel flow increases. Therefore, a lesser amount of steam can be generated in the HRSG and correspondingly lesser network is obtained. The network is further reduced by the work required for the steam compressor. Since, the required amount of IP steam for CLR system cannot be produced at higher fuel flow rates, more and more LP steam is supplied to the steam compressor as the fuel flow rate increases to turn it into IP steam. This increases the work input to the compressor and eventually, reducing the network output. As a result, at higher fuel flow rate, not enough power can be produced to self-sustain the plant but some power from outside is required as shown by the negative values of the electrical efficiency.

$\mathrm{H}_{2}$ efficiency increases as the fuel flow rate is increased as shown in Fig. 3. The increase is due to the increase in formation of $\mathrm{FeO}$ in the fuel reactor. Since, $\mathrm{FeO}$ and $\mathrm{Fe}_{3} \mathrm{O}_{4}$ has been assumed as the solid products from the FR, at lower fuel flow rate $\mathrm{FeO}$ is produced along with some amount of $\mathrm{Fe}_{3} \mathrm{O}_{4}$. At higher fuel flow rate, the amount of $\mathrm{Fe}_{3} \mathrm{O}_{4}$ reduces with corresponding increase in the amount of $\mathrm{FeO}$. The solid mixture is separated from the gaseous products by using a cyclone and then supplied to the SR. In the SR, only FeO reacts with steam to give $\mathrm{H}_{2}$. Since, at lower fuel flow rates the amount of $\mathrm{FeO}$ is less, and hence, the $\mathrm{H}_{2}$ yield is also less. It increases as the $\mathrm{FeO}$ increases with corresponding increase in $\mathrm{H}_{2}$ efficiency. The global efficiency include the effect of both electrical and $\mathrm{H}_{2}$ efficiencies. It remain more or less constant since the electrical efficiency and $\mathrm{H}_{2}$ efficiency balances each other.

Fig. 3 also shows the variation in exergetic efficiency with increasing fuel flow rate. The exergetic efficiency of the plant increases with increase in fuel flow rate. This increase is credited to the increase in the chemical exergy of the exhaust $\mathrm{H}_{2}$ stream as the amount of $\mathrm{H}_{2}$ increases with increase in fuel flow rate. This should not be associated with the decrease in the irreversibilities which are very negligible when compared to the increase in exhaust chemical exergy.

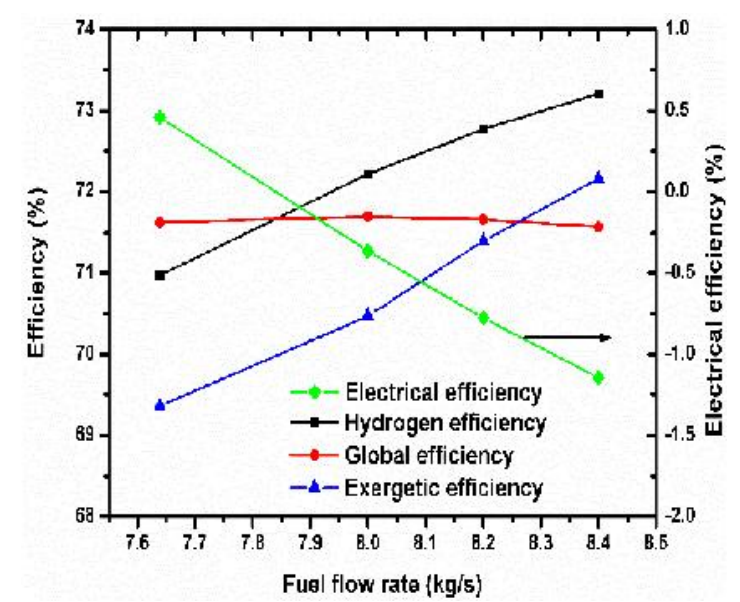

Fig. 3. Plant Performance vs. Fuel Mass Flow $R$ ate

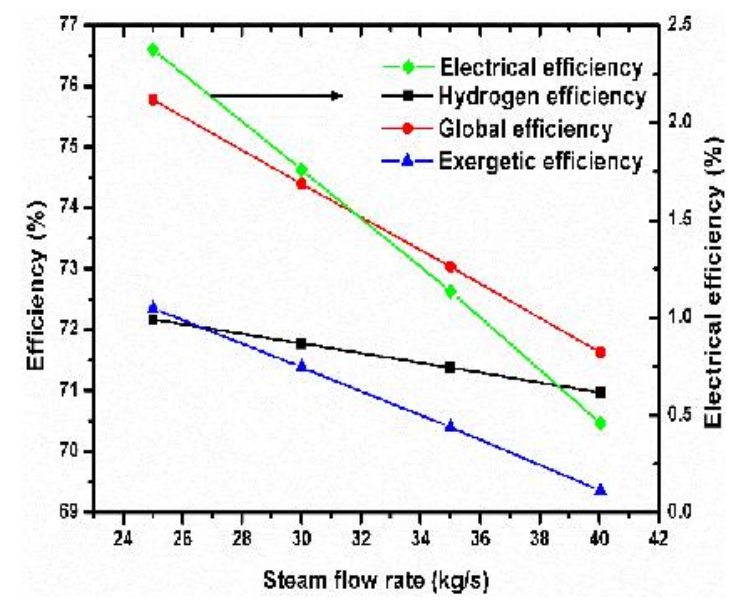

Fig. 4. Plant Performance vs. Steam Mass Flow Rate

\subsection{Effect of Steam Mass Flow Rate}

The base case value of steam mass flow rate is almost twice of the stoichiometric amount. This is to ensure higher steam conversion rates. However, the equilibrium conditions does not require that amount of steam. Therefore, the amount of steam can be reduced without compromising the steam conversion rates. In this study, the values chosen are higher than the stoichiometric amount. The steam flow rate is varied from 25 $\mathrm{kg} / \mathrm{s}$ to $40.04 \mathrm{~kg} / \mathrm{s}$, the latter being the base case value. The plant performance (electrical, $\mathrm{H}_{2}$ and exergetic efficiencies) are depicted in Fig. 4. It can be seen from the figure that the electrical efficiency decreases as the steam flow rate reaches the base case value. In all the cases, there is no negative electrical efficiency as is the case in higher fuel flow rates. Very high temperatures are obtained in the exhaust of the three reactors at lower values of steam flow rate, which are suitable to produce more and more steam and consequently more and more power. Also, the amount of LP steam through the steam compressor is reduced as less steam is required by the SR in the CLR loop. The decrease in net work with the increase in steam flow rate can be observed from Table 3.

$\mathrm{H}_{2}$ efficiency decreases with increase in steam flow rate. As the temperatures are high at lower steam flow rates, the amount of $\mathrm{H}_{2}$ produced at equilibrium is higher than that at lower temperatures. Higher steam flow rates produce lower temperature exhausts in CLR system and correspondingly less amount of $\mathrm{H}_{2}$ is produced. Though the variation is not that 
significant but it will have an effect on the global efficiency. This shows that the temperature plays an important role in steam conversion to $\mathrm{H}_{2}$. The effect can be better explained by considering that the amount of $\mathrm{FeO}$ produced in the FR decreases with increasing steam flow rate. As mentioned earlier, $\mathrm{Fe}_{3} \mathrm{O}_{4}$ does not participate in the exothermic reaction with steam in the SR, as a result only $\mathrm{FeO}$ reacts with steam to produce $\mathrm{H}_{2}$. Ultimately, it comes down to the amount of $\mathrm{FeO}$ present in the SR. The global efficiency also follow the similar trend as it consists of both the electrical and $\mathrm{H}_{2}$ efficiencies.

The exergetic efficiency also decreases with increase in steam flow rate as shown in Fig. 4. The decrease is due to increase in the irreversibilities in the plant components. In addition, the output chemical exergy of the $\mathrm{H}_{2}$ in the exhaust and the pure exergy of network decreases as mentioned above. Hence, the exergetic efficiency also decreases.

\subsection{Effect of Air Mass Flow Rate}

The plant performance efficiencies for the variation in air flow rate are shown in Fig. 5. The air flow rate is varied from 45$59.37 \mathrm{~kg} / \mathrm{s}$. The latter one being the base case value which is selected to ensure the complete oxidation of OC in the AR. But this amount is about 1.5 times higher than the stoichiometric requirement. The network produced as the air flow rate is varied, is given in Table 3. At lowest air flow rate, the network produced is very high about $2.63 \mathrm{MW}$ while that at highest air flow rate, it is about $1.59 \mathrm{MW}$. The difference is significant which is evident from the electrical efficiencies in Fig. 5. Higher air flow rates dilute the high temperature gases and eventually gives lower electrical efficiencies. As the amount of air is lower, the temperature in the reactors is significantly higher than that higher air flow rates. The high temperatures aid in producing more steam in the HRSG and consequently, producing more power through steam turbines. Large amounts of IP steam required by the CLR system can be produced just from the HRSG, which reduces the amount of LP steam flow through the steam compressor. As a result, the work input to the steam compressor is low and increases as the air flow rate increase.

The variation in $\mathrm{H}_{2}$ efficiency is not significant as shown in Fig. 5. At lower air flow rates, since the temperature in the reactors is high, more $\mathrm{FeO}$ is produced in the FR and consequently, more $\mathrm{H}_{2}$ is produced. On the other hand, if the air flow rate is on the higher side, the $\mathrm{FeO}$ production reduces due to formation of $\mathrm{H}_{2}$ and $\mathrm{CO}$ in the $\mathrm{FR}$, which is followed by lower $\mathrm{H}_{2}$ production in the SR. Therefore, as evident from the figure, the $\mathrm{H}_{2}$ efficiency decreases with increasing air flow rate. From the point of view of $\mathrm{CO}_{2}$ capture, higher air flow rates reduces the FR temperature and fuel conversion efficiency and as a result, the $\mathrm{CO}_{2}$ stream is contaminated by unwanted products. The global efficiency follows the electrical and $\mathrm{H}_{2}$ efficiencies and decreases with increasing air flow rates as depicted in Fig. 5.

Table 3. Work Output

\begin{tabular}{cc|cc|cc|cc}
\hline $\begin{array}{c}\text { Fuel } \\
\mathrm{kg} / \mathrm{s}\end{array}$ & $\begin{array}{c}\mathrm{W}_{\text {net }} \\
\mathrm{MW}\end{array}$ & $\begin{array}{c}\text { Steam } \\
\mathrm{kg} / \mathrm{s}\end{array}$ & $\begin{array}{c}\mathrm{W}_{\text {net }} \\
\mathrm{MW}\end{array}$ & $\begin{array}{c}\text { Air } \\
\mathrm{kg} / \mathrm{s}\end{array}$ & $\begin{array}{c}\mathrm{W}_{\text {net }} \\
\mathrm{MW}\end{array}$ & $\begin{array}{c}\mathrm{OC} \\
\%\end{array}$ & $\begin{array}{c}\mathrm{W}_{\text {net }} \\
\mathrm{MW}\end{array}$ \\
\hline 7.63 & -1.59 & 25 & -8.25 & 45 & -2.63 & 0 & -0.028 \\
8 & 1.33 & 30 & -6.11 & 50 & -2.26 & 2 & -1.59 \\
8.2 & 2.9 & 35 & -3.94 & 55 & -1.86 & 10 & -8.11 \\
8.4 & 4.37 & 40.04 & -1.59 & 59.37 & -1.59 & 15 & -12.21 \\
\hline
\end{tabular}

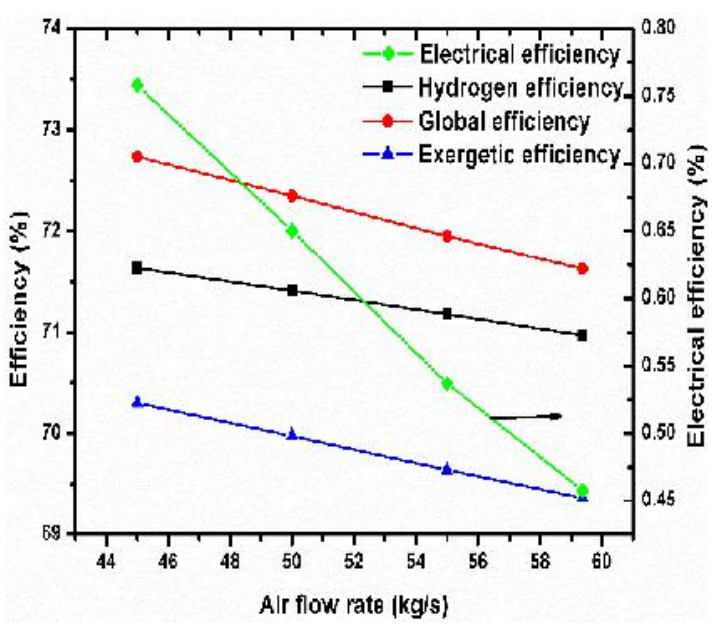

Fig. 5. Plant Performance vs. Air Mass Flow Rate

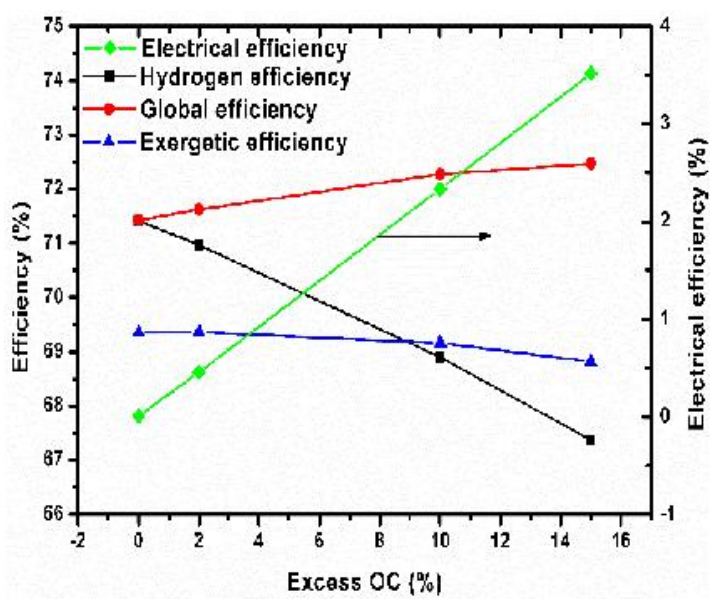

Fig. 6. Plant Performance vs. Excess OC

The exergetic efficiency variation is not significant but it decreases with increasing air flow rates. The initial high exergetic efficiency is due to the fact that the total irreversibilities are lower at lower air flow rates whereas the irreversibilities become higher as the air flow rate increases. To be precise the irreversibilities occur in gas turbine-compressor turbocharger where the irreversibilities directly depends on the amount of the air supplied. In addition to the irreversibilities, the $\mathrm{H}_{2}$ output at lower air flow rates is slightly higher than that at the higher flow rates. This corresponds to high output chemical exergy in $\mathrm{H}_{2}$ exhaust stream resulting in high exergetic efficiency.

\subsection{Effect of Excess OC}

The base case OC flow rate is in excess of $2 \%$ to allow the complete conversion of fuel in the FR based on the experimental observations of Chiesa et al. [8]. They have also reported that increasing the amount of $\mathrm{OC}$ increases the reactor temperatures which will help in producing more steam in the HRSG and more power in the steam turbines. The excess OC is varied from 0-15 $\%$. Zero corresponds to the stoichiometric value while the base case value is $2 \%$. The results obtained for the efficiencies are plotted in Fig. 6. The results show that the electrical efficiency increases significantly. This is because of increase in the reactor temperatures which consequently helps in producing large amount of steam in the HRSG while lowering the work input to 
the steam compressor. The network produced is shown in Table 3. However, there is a negative effect of increasing the amount of OC. The OC in the FR is not completely reduced to $\mathrm{FeO}$, due to the presence of large amount of $\mathrm{Fe}_{2} \mathrm{O}_{3}$, significant amount of $\mathrm{Fe}_{2} \mathrm{O}_{3}$ is converted to $\mathrm{Fe}_{3} \mathrm{O}_{4}$. But $\mathrm{Fe}_{3} \mathrm{O}_{4}$ does not participate in the reaction with steam. Hence, as a result, $\mathrm{H}_{2}$ production decreases as the amount of OC increases which is depicted by the $\mathrm{H}_{2}$ efficiency in the figure. The global efficiency shows the net performance of the plant. It increases as the OC flow rate increases. Since, the aim of this technology is to produce $\mathrm{H}_{2}$, there should not be any compromise in producing larger amounts of $\mathrm{H}_{2}$. Hence, the amount of OC should be little above the stoichiometric amount as suggested by Chiesa et al [8].

The exergetic efficiency is not affected much by the change in the amount of OC supplied. The general trend is that it decreases slightly as the amount of OC increases. It is balanced by the increase in net work and decrease in $\mathrm{H}_{2}$ production.

\section{Conclusions}

A thermodynamic model of a plant has been made in Aspen plus consisting of a chemical looping reforming system, heat recovery steam generator, steam turbine and compression system. The model is tested by varying the key operating parameters such as mass flow rates of fuel, steam, air and OC. The results obtained can be used to find the optimum parameters which will give the best performance of the plant based on the electrical, $\mathrm{H}_{2}$ and exergetic efficiencies.

The results show that the electrical efficiency depends on the amount of steam produced which in turn depend on the reactor temperatures. The electrical efficiency decreases with increase in fuel, steam and air mass flow rate whereas it increases with increase in the amount of OC supplied. On the other hand, the $\mathrm{H}_{2}$ efficiency also depends on the reactor temperatures and it decreases with increasing flow rates of steam, air and the OC. $\mathrm{H}_{2}$ efficiency increases with increase in fuel flow rate. The global efficiency shows the net effect of the electrical and $\mathrm{H}_{2}$ efficiency on the plant performance. It decreases when both the electrical and $\mathrm{H}_{2}$ efficiencies decrease as in the cases of fuel and OC flow rates and remains almost constant as it is balanced by the increasing $\mathrm{H}_{2}$ efficiency and decreasing electrical efficiency as in the cases of steam and air flow rates. The exergetic efficiency is found to decrease for the cases of steam, air and $\mathrm{OC}$ flow rates while it is found to increase with increase in fuel flow rate.

\section{Acknowledgment}

This research was supported by the Government of Abu Dhabi to help fulfil the vision of the late President Sheikh Zayed Bin Sultan Al Nahyan for sustainable development and empowerment of the UAE and humankind.

\section{References}

[1] Nouni MR. Hydrogen energy and fuel cell technology: Recent developments and future prospects in India. Renewable Energy Akshay Urja report, 2012.

[2] K. Chandrasekhar, Y.J. Lee, D.W Lee. Biohydrogen production: Strategies to improve process efficiency through microbial routes. Int. J. Molecular Sciences 2015;16:8266-93, DOI: 10.3390/ijms16048266
[3] Jong WD. Sustainable hydrogen production by thermochemical biomass processing. Chapter 6, 2008, pp. 185-225.

[4] W.H. Chen, Y.J. Syu. Hydrogen production from water gas shift reaction in a high gravity (Higee) environment using a rotating packed bed. Int. J. Hydrogen Energy 2010;35:10179-89, 10.1016/j.ijhydene.2010.07.126

[5] Hydrogen Generation Market by Geography, by Mode of Generation \& Delivery, Applications and Technology - Global Trends \& Forecasts to 2019. Report Code: EP2781, September 2014.

[6] H.J. Ryu, G.T. Jin. Chemical looping hydrogen generation system: Performance estimation and process selection. Korean J. Chemical Engineering 2007;24(3):527-31, DOI: 10.1007/s11814-007-0093-8

[7] Gielen, D and Simbolotti, S: Prospects of hydrogen and fuel cells. International Energy Agency, 2005. DOI: 10.1787/9789264109582-en

[8] P. Chiesa, G. Lozza, A. Malandrino, M. Romano, V. Piccolo. Three-reactor chemical looping process for hydrogen production. Int. J. Hydrogen Energy 2008;33:2233-45, 10.1016/j.jijhydene.2008.02.032

[9] W. Xiang, S. Chen, Z. Xue, X. Sun. Investigation of coal gasification hydrogen and electricity co-production plant with three-reactors chemical looping process. Int. J. Hydrogen Energy 2010;35:8580-91, DOI: $10.1016 /$ j.j.jhydene.2010.04.167

[10] CC. Cormos. Hydrogen production from fossil fuels with carbon capture and storage based on chemical looping systems. Int. J. Hydrogen Energy 2011;36:5960-71, 10.1016/j.ijhydene.2011.01.170

[11] M.N. Khan, T. Shamim. Investigation of hydrogen generation in a three reactor chemical looping reforming process. Applied Energy (2015), DOI: 10.1016/j.apenergy.2015.08.033

[12] M. Anheden, G. Svedberg. Exergy analysis of chemicallooping combustion systems. Energy Conversion 1998;39:1967-80, DOI: $\quad$ 10.1016/S01968904(98)00052-1

[13] Hassan B and Shamim T. Parametric and exergetic analysis of a power plant with $\mathrm{CO}_{2}$ capture using chemical looping combustion. International Conference on Clean and Green Energy 2012. Singapore.

[14] A.P. Simpson, A.E. Lutz. Exergy analysis of hydrogen production via steam methane reforming. Int. J. Hydrogen Energy 2007;32:4811-20, DOI: 10.1016/j.jijhydene.2007.08.025

[15] B. Selcuk. Calculation and interpretation of the standard chemical exergies of elements using the chemical reference species. Acta Phys Chim Sin 2009;25:1645-9. 